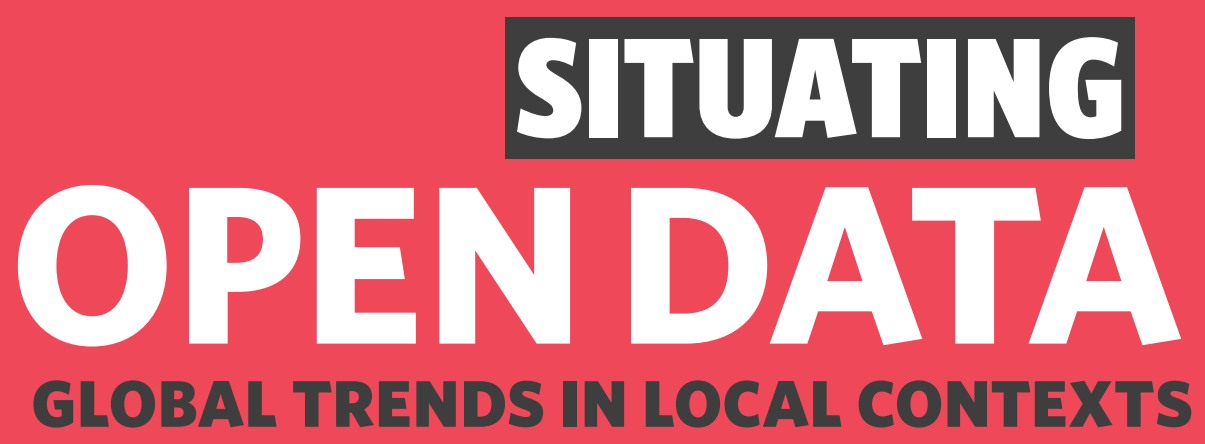

Edited by Danny Lämmerhirt, Ana Brandusescu, Natalia Domagala \& Patrick Enaholo 


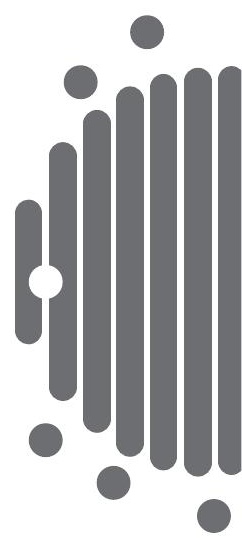

\section{Situating Open Data Global Trends in Local Contexts}

Edited by

Danny Lämmerhirt, Ana Brandusescu, Natalia Domagala \& Patrick Enaholo 
Published in 2020 by African Minds

4 Eccleston Place, Somerset West 7130, Cape Town, South Africa

info@africanminds.org.za

www.africanminds.org.za

This work is published under a Creative Commons Attribution 4.0 International License (CC-BY).

ISBN Paper 978-1-928502-12-8

ISBN eBook 978-1-928502-13-5

ISBN ePub 978-1-928502-14-2

Orders:

African Minds

4 Eccleston Place, Somerset West 7130, Cape Town, South Africa

info@africanminds.org.za

www.africanminds.org.za

For orders from outside South Africa:

African Books Collective

PO Box 721, Oxford OX1 9EN, UK

orders@africanbookscollective.com

www.africanbookscollective.com 


\title{
6. \\ The cost of late payments in public procurement
}

\author{
Juan Pane, Camila Salazar \& Julio Paciello
}

Open public procurement data has gained attention in the past years as a way of increasing transparency and helping governments improve their procurement practices. According to the latest report by the Open Contracting Partnership (2017: 3), in 2017 over 30 countries were publishing data following the open contracting data standard. Our analysis is a case study of how open data of public procurement, when analysed and re-used, can yield useful inputs to identify inefficiencies in the procurement process, recommend structural reforms to improve the procedures and drive cost savings for the public administration.

Following the Open Contracting Data Standard (OCDS), the publication of contracting data should include the different stages of the procurement process that go from the bid preparation (planning) and tender, to the implementation of the contract. For this chapter, we focus on the last stage, particularly the financial implementation which relates to the process of payment to suppliers. In this phase, governments sometimes face the problem of not paying suppliers on time, which causes inefficiencies and financial costs. Failure to pay invoices promptly generates a negative effect on firms that provide goods, services and public works to the government, causing short-term liquidity problems. This might force businesses to turn to the financial market to cover their obligations, use their savings, or go out of business (World Bank 2017). If money is lent from the financial market, providers incur extra costs due to interest rates, which might be included in the cost structure of the provider, implying an extra cost for the public administration. In addition, this practice can ultimately affect economic growth (Checherita-Westphal et al. 2016). Moreover, if this procedure becomes the norm, suppliers may decline to do business with the government, reducing 
competition, and thus the possibility of obtaining better value for money for the purchasing entity (World Bank 2017).

Previous work on public procurement payments has focused on measuring arrears in national accounts (Diamond \& Schiller 1987) and on how governments can prevent and manage payment delays (Flynn \& Pessoa 2014). There are also specific country reports that analyse public procurement payment systems (World Bank 2008, 2017; Giussani et al. 2016). On the other hand, ChecheritaWestphal et al. (2016) use annual data from 17 European countries and a proxy for government arrears to calculate the economic impact; and Connell (2014) estimates the cost of late payments on government to business transactions for 26 European countries. Other works have studied inefficiencies in other stages of the procurement process (Balaeva \& Yakovlev 2017; Fiordelisi et al. 2012) or analysed late payments in the private sector (Smirnov 2016).

This chapter estimates the financial cost of late payments in public procurement and identifies variables that can affect them. Contrary to previous work that used proxy variables to calculate the cost, we analysed 599354 detailed payments of 59 public institutions from 2011 to 2017 released using open data formats from the National Treasury of Paraguay (datos.hacienda.gov.py). We used a set of methodologies for cost analysis readily available in the literature and adapted them to the data availability, to show how this can be replicated in different countries, using the Paraguayan data as a case study. Our calculation follows Connell's (2014) approach, to estimate the cost of late payments on firms and on the public administration but focusing on a single country (Paraguay) for a seven-year period, given the rich information about the payment process released at datos.hacienda.gov.py. ${ }^{1}$ In addition, we use survival analysis, a technique that allows us to model payment duration and to identify which variables have an impact in delaying payments. The preliminary findings show that the median duration from the moment an invoice is issued to when the payment occurs via a bank transfer to the supplier's bank account can be of approximately 55 days for each payment. In comparison, international practice considers 30 days an acceptable payment period (Flynn \& Pessoa 2014). Moreover, our analysis on the historical data shows that the cost of late payments is of approximately USD 81.07 million in the analysed time frame, which could be cut down if some of the steps in the payment process are analysed and the appropriate normative framework is created.

Our work aims to encourage the publication of open public procurement payment data by showing how this information can be analysed to reduce costs in the public procurement process. Our methodology could be replicated in other

1 We used the following datasets: payroll of officials (https://datos.hacienda.gov.py/data/ nomina), national budget (https://datos.hacienda.gov.py/data/pgn-gasto), list of invoices (https://datos.hacienda.gov.py/data/obligacion), transfer request orders (https://datos.hacienda. gov.py/data/str), transfer orders (https://datos.hacienda.gov.py/data/orden-transferencia). 
countries that have already published payment data in open formats. Some of the limitations of our study are that we lack the exact invoice due date, specific information about the providers and that we do not have payment information about all the public institutions in the country.

This chapter is structured as follows: section 2 describes the state of the art related to our problem of study; section 3 explains the data and methods used for the analysis, transformations made to the variables and limitations of the study. Section 4 shows the results of the analysis and section 5 presents the conclusions and future work.

\section{State of the art}

The current state of the art on public procurement payments has mostly focused on discussing the issue of government arrears, on measuring the economic impact and financial cost of late payments for several countries and on analysing other stages of the procurement process.

\section{The problem of arrears}

The International Monetary Fund (IMF) has addressed the issue of late payments in different reports. Flynn and Pessoa (2014) analysed how governments can prevent and manage expenditure arrears, which includes payments to private contractors. According to the report, one of the biggest issues on managing arrears is that what is considered a delay may vary between countries and is dependent on the maturity of the payment system. They also list the impact chronic arrears may have at an aggregated level, which includes reduced economic growth, increased cost of service provision, reduced or interrupted public delivery and increased interest rates, among others. However, these effects are discussed theoretically and not measured empirically.

On the other hand, Ramos (1998) focused on how governments can address the arrears problem with securitisation in order to provide temporary relief from debt service obligations and increase government credibility.

For the specific case of Paraguay, the World Bank (2008: 62) pointed out in a fiduciary assessment that improvements were needed in the public procurement payment management system, since a relevant percentage of contracts were in arrears: 'The delay in effecting payment negatively impacts the willingness to participate in public PR processes or is reflected in quoting higher prices, discounting the financial costs associated to these delays, thus producing inefficiencies to the system'. In 2016, another assessment (Giussani et al.) pointed out that the volume of arrears (of all government expenditure) was around 9.68\% of total expenditure, when the recommended percentage is of $2 \%$. In addition, they cited a report by the public comptroller, which had estimated a 20 -day average delay. 
More recently, a World Bank's public procurement report (2017) presented comparable data on public procurement regulations across 180 economies; they divided the analysis in eight pillars, one of which was the payment of suppliers. In this category, Paraguay received a score of 48 out of 100 - the lowest score in all the indicators measured, since the actual time for suppliers to receive payment was between 31 and 90 days. In addition, there were no automatic penalties paid to the suppliers in the case of a delay and the time to process the payment did not start from the submission of invoice, which can slow down the payment arbitrarily.

\section{Cost and impact of late payments}

To the best of our knowledge, the cost of late payments in the public sector has yet to be explored in Latin America, and recent studies have measured the economic impact of late payments in European countries. For instance, ChecheritaWestphal et al. (2016) used annual data from 17 European countries and a proxy for government arrears to calculate its economic impact. They discovered that payment delays reduce economic growth, increase the likelihood of bankruptcies and reduce profits. For instance, a one standard deviation change in delayed payments reduces the growth rate by 0.8 to 1.5 percentage points and reduces profit growth by 1.5 to 3.4 percentage points. Additionally, they found that the larger the delayed payments, the higher the probability of default among private companies. Because of the cross-country and short time period data, they used dynamic panel models and a Bayesian VAR to estimate these effects.

Additionally, Connell (2014) estimated the cost of late payments on government to business transactions at an aggregated level, also in the European context. The study calculated the short-term financial cost, applying annual interest rates to the claims against the public administration (which serves as a proxy for the payment delays), times the average delay. This approach to calculate aggregated costs is useful for our estimation, with the difference being that we focus on a single country. Furthermore, Connell (2014) calculated the impact these delays may have on the exit rate of firms, using the ratio between the number of deaths of enterprises and the total number of firms in a given country, across several years. The result shows that a 1-point reduction in the delay ratio leads to a decrease in exit rates of about 1.7 percentage points.

A limitation found in these studies is the lack of full information regarding government payments, so the estimation is made using a proxy. On the contrary, we have micro-level data about each payment which allows us to calculate the aggregate cost more precisely.

Furthermore, Fiordelisi et al. (2012) calculated the cost for the Italian economic system resulting in the delay of trade loans by the public administration. The study explored different scenarios according to different payment times and estimated the financial cost using the interest rate multiplied by the delay and 
volume of credits towards the public administration. In addition, they estimated the aggregate social cost comparing this value with the expenditure the government would have faced to pay on time, using the rate on Treasury bills.

On the other hand, Valcani Vicari Associati et al. (2015) evaluated whether the 2011 European Union Late Payment Directive had accomplished its objective of reducing payment times in 28 countries in Europe. They found that after four years of implementation, the average duration had fallen from 65 days on average in 2011 to 58 days in 2014, but stayed beyond the 30-day optimal deadline: 'Rather than legislation, national business culture, economic conditions and power imbalances are the driving factors for payment behaviour' (2015: 68). This is a relevant result for our investigation, since it is important to consider other factors besides legislation in order to drive change in the payment culture. They also found that firms that had the government as a main client were more likely to have difficulties paying to their suppliers, which indicates that late public payments can have an impact on a larger supply chain.

\section{Inefficiencies in public procurement}

The literature on public procurement also includes several studies which analyse the cost and efficiency of the public procurement process, and not exclusively of the payment stage. Some of these works use data envelopment analysis (DEA), a method that is generally used to estimate a production cost function, with minimal assumptions. This methodology calculates an efficiency frontier for a set of units using different inputs and outputs, and then gives an efficiency score (it considers efficiency as the lowest input amount to produce one unit of output). Guccio et al. (2012) used this method to investigate the performance of Italian public contracts in terms of time of completion of works and cost overruns.

We find more useful the approach used by Strand et al. (2011) and Balaeva and Yakovlev (2017). They analyse the cost and effectiveness of public procurement in the European Union and Russia using estimates of person-days spent in the procurement process, and then they applied data of employee remuneration to calculate the labour costs and the total costs of the procurement. In their regard, shorter procedure times indicate higher efficiency. This methodology can be adapted to analyse exclusively the payment stage of the process. However, we could not implement this methodology due to lack of data.

Finally, another set of studies have analysed delays in other stages of the public procurement process. For instance, Gori et al. (2017) explored the variables that affect the duration of public works in Italy using survival analysis and found that the lack of experience of local governments results in a higher delay probability in the execution of the contract. On the other hand, Smirnov (2016) proved survival analysis is a good approach to model late invoice payment times in the private sector. Given the similarity of the transaction, this approach can be used to model government to business payments. 


\section{Methodology}

\section{Data description}

The public procurement payment process in Paraguay consists of three different stages. The first one comprises the period from when the invoice is issued until it is approved by the procuring entity (Invoice stage). In the second stage, a transfer request (TR stage) is generated, and it is then sent to the Treasury. In the final stage, the Treasury creates a transfer order (TO stage) and then makes the payment to the contractor via bank transfer. The first two stages happen inside the procuring entity, while the last stage is the charge of the Treasury. There are also intermediate stages in each of the steps, illustrated in Figure 1.

Figure 1. Payment process steps

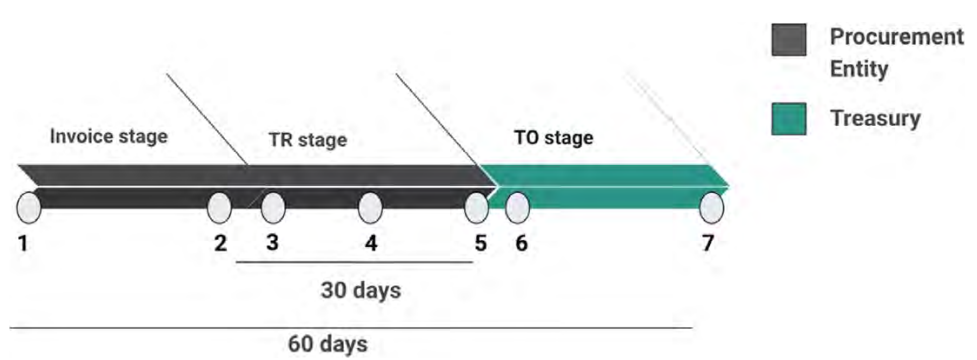

Where:

1. Invoice creation (receipt of invoice) (obl_fecha elaboracion) ${ }^{2}$

2. Invoice approval (obl_fecha_aprobacion)

3. TR creation (str_fecha_ingreso)

4. TR approval (str_fecha_aprobacion)

5. TR transfer to Treasury (str_fecha_recepcion_tesoro)

6. TO creation (ot_fecha_generacion)

7. Payment (ot_fecha_deposito)

The process is as follows: the provider presents the invoice to the procurement entity (1) and then has to wait until the institution creates an obligation for the invoice and approves it (2). For one or more obligations, a transfer request (TR) is created (3), it is then approved (4) and finally the procurement entity sends it to the Ministry of Finance (Treasury) for payment (5). Therefore, for one or more TR's the Treasury creates a transfer order (TO) (6), and then executes the payment (7).

2 In parenthesis, we add the variable name derived from the dataset. All the variables are explained in Table 1. 
According to the IMF, 'international practice on what is an acceptable delay between receipt and payment of the invoices varies from anywhere between 30 to 120 days' (Flynn \& Pessoa 2014: 4). In addition, the World Bank (2017) reported that most suppliers in high-income economies receive payments in less than 30 days.

In Paraguay, there is not a single deadline in laws or regulations, from receipt of invoice to payment, and the specific deadline is stipulated in each contract. However, according to the executive order $8452 / 2018$, the TR stage has a $30-$ day deadline. In addition, the DNCP order 1024/11 about General Conditions of the Contract (Pliego estándar de contratación) states that the contracting party will execute the payments as soon as possible, but in no case may it exceed sixty days after receipt of invoice or request of payment, and after the contracting party has accepted the request. The acceptance or rejection of the invoice must be given no later than fifteen days after its presentation. ${ }^{3}$ These 15 days are before the process starts and the invoice is created. This means that the whole payment process can last 60 days, if not specified otherwise in the contract. In addition, according to Law 2051 and the General Conditions of the Contract, if the payment is delayed, the contractor has to recognise financial interests to the provider, which implies an additional cost for the public administration.

According to this legislation, the regulation of payment times is not clear, which can contribute to long costly delays. For our analysis, we consider the following delays and deadlines:

Table 1. Stages and deadlines of the payment process

\begin{tabular}{|c|c|c|}
\hline Stage/Delay & Description & $\begin{array}{l}\text { Deadline in } \\
\text { regulations }\end{array}$ \\
\hline Invoice stage & $\begin{array}{l}\text { Time between the issue of the invoice and its approval in the procuring } \\
\text { entity. (2) }-(1)^{4}\end{array}$ & $\begin{array}{l}\text { No specific } \\
\text { deadline }\end{array}$ \\
\hline TR stage & $\begin{array}{l}\text { Time between the issue of the TR and its dispatch to the Treasury. } \\
\text { (5) - (3) }\end{array}$ & 30 days \\
\hline $\begin{array}{l}\text { TR creation } \\
\text { delay }\end{array}$ & $\begin{array}{l}\text { Time between the approval of the obligation (invoice) in the procuring } \\
\text { entity and the TR creation. (3) - (2) }\end{array}$ & $\begin{array}{l}\text { No specific } \\
\text { deadline }\end{array}$ \\
\hline $\begin{array}{l}\text { TR approval } \\
\text { delay }\end{array}$ & Time between the TR creation and its approval. (4) - (3) & $\begin{array}{l}\text { No specific } \\
\text { deadline }\end{array}$ \\
\hline $\begin{array}{l}\text { Transfer to } \\
\text { Treasury delay }\end{array}$ & Time between the TR's approval and its dispatch to the Treasury. (5) - (4) & $\begin{array}{l}\text { No specific } \\
\text { deadline }\end{array}$ \\
\hline TO stage & $\begin{array}{l}\text { Time between the issue of the transfer order and the final payment. } \\
(7)-(6)\end{array}$ & $\begin{array}{l}\text { No specific } \\
\text { deadline }\end{array}$ \\
\hline $\begin{array}{l}\text { TO creation } \\
\text { delay }\end{array}$ & $\begin{array}{l}\text { Time between the TR's dispatch to the Treasury and the creation of the } \\
\text { TO. (6) - (5) }\end{array}$ & $\begin{array}{l}\text { No specific } \\
\text { deadline }\end{array}$ \\
\hline Payment delay & Time between the creation of the TO and the final payment. (7) - (6) & $\begin{array}{l}\text { No specific } \\
\text { deadline }\end{array}$ \\
\hline Total delay & Time between the issue of the invoice and the final payment. (7) - (1) & 60 days \\
\hline
\end{tabular}

3 Own translation.

4 Steps detailed in Figure 1. 
For this analysis, we used the following datasets of public institution payments between 2011 to 2017 in Paraguay, available in the open data portal of the treasury (datos.hacienda.gov.py):

- List of obligations (Listado de obligaciones, available at https://datos. hacienda.gov.py/data/obligacion), a dataset with information about each invoice;

- Transfer request (Solicitud de transferencia de recursos, available at https://datos.hacienda.gov.py/data/str), a dataset with all the requests that are generated in the entity for one or several payment obligations to the provider. Each transfer request (TR) can have one or more invoices; and

- List of transfer orders (Listado de órdenes de transferencia, available at https://datos.hacienda.gov.py/data/orden-transferencia), which has the detail of each transfer order, an instrument through which the delivery of funds to the beneficiary is made. Each transfer order can have one or more transfer requests.

The above datasets were combined using a unique identifier, where the observation unit was given by each invoice. The dataset had information about each invoice, the contracting procedure and the provider. We also used two other datasets from the treasury's open data portal to obtain two variables about the institutional budget execution ${ }^{5}$ and the number of officials working in each entity. ${ }^{6}$ These served as proxies for the institution size and its efficiency using public resources.

The initial dataset had 599369 observations. However, we found several errors, which we validated with the Treasury officials. In the cases where these errors could not be corrected, we eliminated the observations. We made the following transformations to clean the data: ${ }^{7}$

- We eliminated the observations with empty date values and those in which the date of the invoice was before the date of the contract.

- After creating variables for the delays, we obtained several negative values in the duration. We eliminated these observations, since we could not correct the error.

- We eliminated observations where the duration of the payment was less than 10 days, an unlikely scenario; and observations where the sum of the invoice was less than 50000 guaranies (USD 9).

5 https://datos.hacienda.gov.py/data/pgn-gasto

6 https://datos.hacienda.gov.py/data/nomina

7 See section 3 in http://rpubs.com/camilamila/late_payments 
In addition, we identified outliers ${ }^{8}$ in each of the stages of the process and created two other datasets:

- Dataset A, the main dataset without the outliers and 84\% (315 983) of the observations. ${ }^{9}$

- Dataset B, a dataset with the outliers and 61537 observations. In this dataset, $55 \%$ of the observations were from the Ministry of Health.

We decided to segment the dataset into two, since the longer delays we have in dataset B, correspond to less frequent cases, that do not reflect the payment practices of most of the institutions in the sample. However, all the analyses were run on the full dataset and in some cases, we present the results separating by the dataset; whenever this occurred, we specified it in each of the tables and the figures in the Results section.

After the transformation, the datasets had the following variables:

Table 2. Variables used in the analysis

\begin{tabular}{|c|c|c|}
\hline Variable name & Description & Type \\
\hline obl_id & Unique id for each invoice & string \\
\hline obl_fecha elaboracion & Invoice creation date & POSIXct \\
\hline obl_fecha_aprobacion & Invoice approval date & POSIXct \\
\hline str_fecha_ingreso & TR creation date & POSIXct \\
\hline str_fecha_aprobacion & TR approval date & POSIXct \\
\hline str_fecha_recepcion_tesoro & TR transfer to Treasury date & POSIXct \\
\hline ot_fecha_generacion & TO creation date & POSIXct \\
\hline ot_fecha_deposito & Payment date & POSIXct \\
\hline obl_monto_obligado & Amount of each invoice (includes deductions) & num \\
\hline obl_anho_obligacion & Year of the invoice & num \\
\hline obl_codigo_contratacion & Code of the contracting procedure & string \\
\hline obl_moneda_descripcion & Invoice currency & string \\
\hline obl_entidad_descripcion & Procuring entity & string \\
\hline funds & $\begin{array}{l}\text { Type of funds used to pay the invoice: } 1=\text { Institutional funds, } \\
2=\text { Treasury funds, } 3=\text { public credit funds }\end{array}$ & factor \\
\hline purchase & $\begin{array}{l}\text { Type of purchase: } 1=\text { services, } 2=\text { goods and materials, } \\
3=\text { exchange goods, } 4=\text { =investment, } 5=\text { transfers }\end{array}$ & factor \\
\hline contr_monto_adjudicado & Total amount of the contract to which the invoice belongs & num \\
\hline contr_fecha_firma_contrato & Date of signature of the contract & POSIXct \\
\hline prov_ruc & Unique id of the provider & string \\
\hline total & Total duration of the payment in days & num \\
\hline r_factura & Total duration of the invoice stage & num \\
\hline
\end{tabular}

8 A value was considered the outlier if it was higher than $\mathrm{Q} 3+1.5 * \mathrm{IQR}$, where $\mathrm{Q} 3$ equals the 75 th percentile of the distribution and IQR is the interquartile range.

9 The datasets used for the analysis can be downloaded from: https://drive.google.com/ open?id=1Qhr_LPIoTyJa8L19kI_OnL-tIaoikjYn 


\begin{tabular}{l|l|l}
\hline Variable name & Description & Type \\
\hline r_str & Total duration of the TR stage & num \\
\hline r_ot & Total duration of the To stage & num \\
\hline r_carga_str & str_fecha_ingreso - obl_fecha_aprobacion & num \\
\hline r_apro_str & str_fecha_aprobacion -str_fecha_ingreso & num \\
\hline r_tesoro_str & str_fecha_recepcion_tesoro-str_fecha_aprobacion & num \\
\hline r_carga_ot & ot_fecha_generacion-str_fecha_recepcion_tesoro & num \\
\hline r_pago_ot & ot_fecha_deposito -ot_fecha_generacion & num \\
\hline total_cat & categorical variable of payment times & factor \\
\hline interes & average annual lending rate & num \\
\hline deflator & PIB deflator, base $2017=100$ & num \\
\hline official & Number of officials working in the procuring entity & num \\
\hline ejecucion & $\begin{array}{l}\text { Average annual budget execution percentage (2011-2017) of the } \\
\text { procuring entity }\end{array}$ & num \\
\hline
\end{tabular}

\section{Survival analysis}

We modelled late invoice payments using survival analysis to identify which variables have a role in delaying payments. Survival analysis is a statistical method used to analyse and model the data when the outcome variable is the time until the occurrence of a specific event. In our case, the event of interest is the date of payment of an invoice. These methods have been previously used by researchers to study the duration of public works in Italy (Gori et al. 2017) and to model late invoice payments times in the private sector (Smirnov 2016).

The idea of this approach is that subjects are followed during a time period until the event occurs. The event is called a failure. In this case, $t=0$ is the date the invoice is created and the failure will occur when the payment happens. In the context of survival analysis survival will mean the invoice hasn't been paid yet.

The duration of the state (payment period) is a non-negative random variable called $T$, with a cumulative distribution $\mathrm{F}(\mathrm{t})$ (Cameron \& Trivedi 2005). The probability that the duration of the episode is less than $t$ is:

$$
F(t)=\int_{0}^{t} \square f(s) d s=\operatorname{Prob}(T \leq t)
$$

The probability that the event equals or exceeds $t$, or in our case the probability that the invoice is not paid before time $t$, is given by the survival function:

$$
S(t)=1-F(t)=\operatorname{Prob}(T>t)
$$

We also estimated the hazard function $h(t)$, which is the probability of leaving a state conditional on survival time $t$. That is to say, the rate of success at time $T=t$ given that the invoice has not been paid for up to time $t$. 


$$
h(t)=\frac{\operatorname{Prob}\left(t \leq T \leq t+\frac{\Delta t}{T} \geq t\right)}{\Delta t}=\frac{F(t+\Delta t)-f(t)}{\Delta t S(t)}=\frac{f(t)}{S(t)}
$$

We used the Kaplan-Meier method to estimate the survival function, project the survival curves and estimate the differences between groups. The estimator $S(t)$ is given by:

$$
S(t)=\prod_{t_{i}<t} \frac{n_{i}-d_{i}}{n_{i}}
$$

where $n_{i}$ is the number of survivors at time $t_{i}$ and $d_{i}$ is the number of events that happened until time $t_{i}$.

Finally, to estimate the effect of covariates in survival time, we calculated a parametric model with a Weibull distribution, after testing the fit of different distributions on the data. ${ }^{10} \mathrm{We}$ included the following variables as predictors:

- sum of each invoice (log transform);

- contract sum, (log transform);

- institution, in this case this will be the debtor;

- number of officials, size of the institution payroll;

- budget execution, average budget execution of the entity (contractor);

- type of funds, the financial source used to pay the invoice (categorical variable); and

- type of purchase, segmented in services, goods and materials, investment and others (categorical variable).

These analyses were run excluding the outliers (dataset A).

\section{Financial aggregated cost estimation}

To estimate the short-term aggregated financial cost of late payments for firms, we followed Connell's (2014) approach to calculating this effect on governmentto-business transactions in Europe.

The idea behind this calculation is that private providers need to compensate for the lack of liquidity generated by payment delays. Our assumption is that failure to pay invoices promptly generates a negative effect on providers, causing short-term liquidity problems for firms, and forcing them to turn to the financial market to cover their obligations. In addition, this can be seen as an opportunity cost for firms since, even if they have enough liquidity to face delays, they cannot invest and have to use the money to face the costs of the delay. Moreover, national legislation indicates that providers are entitled to receive interest due to

10 See section 5 in: http://rpubs.com/camilamila/late_payments 
delays, so we assume that if the payment was delayed the public administration had to pay this extra cost.

To obtain the financial cost, we used the annual average lending rate, which is the bank rate that meets the short and medium-term financing needs of the private sector, to the amount of the overdue payment, times the delay expressed as a fraction of a year:

$\mathrm{C}=\mathrm{P}^{*} \mathrm{i}^{*} \mathrm{~d}(5)$

where:

$\mathrm{C}=$ estimated cost for firms

$\mathrm{P}=$ amount of each payment in guaranies

$\mathrm{i}=$ annual average lending rate

$\mathrm{d}=$ delay expressed as a fraction of a year

We consider that a payment is delayed if it is paid after 30 days of the submission of the invoice, which is the maximum payment time that institutions should have according to international recommendations. In addition to the 30-day limit, we also consider the following thresholds for what is considered a delay, according to the deadlines specified in Table 1 and international recommendations:

- 45 days (proposed intermediate deadline);

- 60 days (current maximum deadline in local legislation); and

- 15 days (proposed deadline for the invoice stage).

We calculated the number of invoices that surpassed the mentioned deadlines and then estimated the cost of this delay. Moreover, while we consider that delays occur after 30 days, we assume that even payments that are executed before 30 days imply a cost for firms, since they have to compensate for the lack of liquidity during this period. Thus, we also calculated the total payment duration cost that considers not only late payments (more than 30 days) but the total payment duration. Finally, we also took into account different scenarios, with different payment times, to analyse the possible savings the public administration could have if it modifies its payment regulations.

The cost was then adjusted by inflation using the GDP deflator. Both the data of the average lending rate and the GDP deflator were obtained from the International Financial Statistics website. ${ }^{11}$ The amounts were converted to USD using the average 2017 exchange rate $(5$ 618.933) from the World Bank open data portal. ${ }^{12}$ This approach can be applied to other countries, using these same sources of financial information and local procurement data.

11 Dataset available at: http://data.imf.org/?sk=4C514D48-B6BA-49ED-8AB952B0C1A0179B\&sId=1409151240976

12 https://data.worldbank.org/indicator/PA.NUS.FCRF?locations=PY 


\section{Limitations}

\section{Lack of exact invoice due date}

We did not have the exact due date for each of the invoices, since this data are specified in the contracts. This impedes the ability to calculate the exact due date on the invoices and thus the potential cost that the administration had to recognise in interests to providers. A recommendation to public authorities would be to include this information as part of the public procurement open data.

\section{Information about the providers}

Not having information about the characteristics of the firm (size, sector) can result in an underestimation of the cost, since the interest rates can be different. For simplicity, we used the average lending rate for the private sector. Moreover, having open data about beneficial ownership could help expand the analysis to determine if there are clusters of providers that accumulate contracts.

\section{Institutional data availability}

Even though we have a robust dataset with payment information of 59 institutions that pay through the treasury payment system, this is not a complete sample of all the public institutions, thus the cost is underestimated. The study could be expanded when more institutions provide payment information in open data formats. Finally, we had to discard many observations due to errors on the original dataset. This shows there is still an opportunity to improve the collection and transformation of procurement data in open data formats and implement other validation techniques in order to minimise the errors.

\section{Results}

\section{Descriptive and survival analysis}

\section{Payment duration by stages and funds}

From Table 3 it is determined that only $18.6 \%$ of the invoices issued for public contracts between 2011 and 2017 in Paraguay were paid in 30 days or less. The 30-day deadline is considered an ideal threshold in which payments to providers should be executed. This means that $81.4 \%$ of payments in the analysed period were delayed. On average, public institutions took 55 days to pay invoices. 
Table 3. Invoices paid by payment times (full dataset)

\begin{tabular}{l|c|c}
\hline Payment period (days) & n & Percentage \\
\hline$<30$ & 70402 & $18.6 \%$ \\
\hline $30-<45$ & 67554 & $17.9 \%$ \\
\hline $45-<60$ & 57841 & $15.3 \%$ \\
\hline $60-<75$ & 44468 & $11.8 \%$ \\
\hline 75 or more & 137255 & $36.4 \%$ \\
\hline
\end{tabular}

However, considering the 60-day deadline that payments can have according to regulations, if not specified otherwise on the contract, $48.2 \%$ of payments were delayed. This shows, that even though the payment deadline in Paraguay is twice the period of what is considered an optimal payment time, almost half of all public procurement payments in the analysed period surpassed that limit (see Figure 2). This practice affects providers and the public administration, since this cost might be internalised in the provider's cost structure, and thus the final price of the good, service or public work is higher than expected.

Figure 2. Payment duration
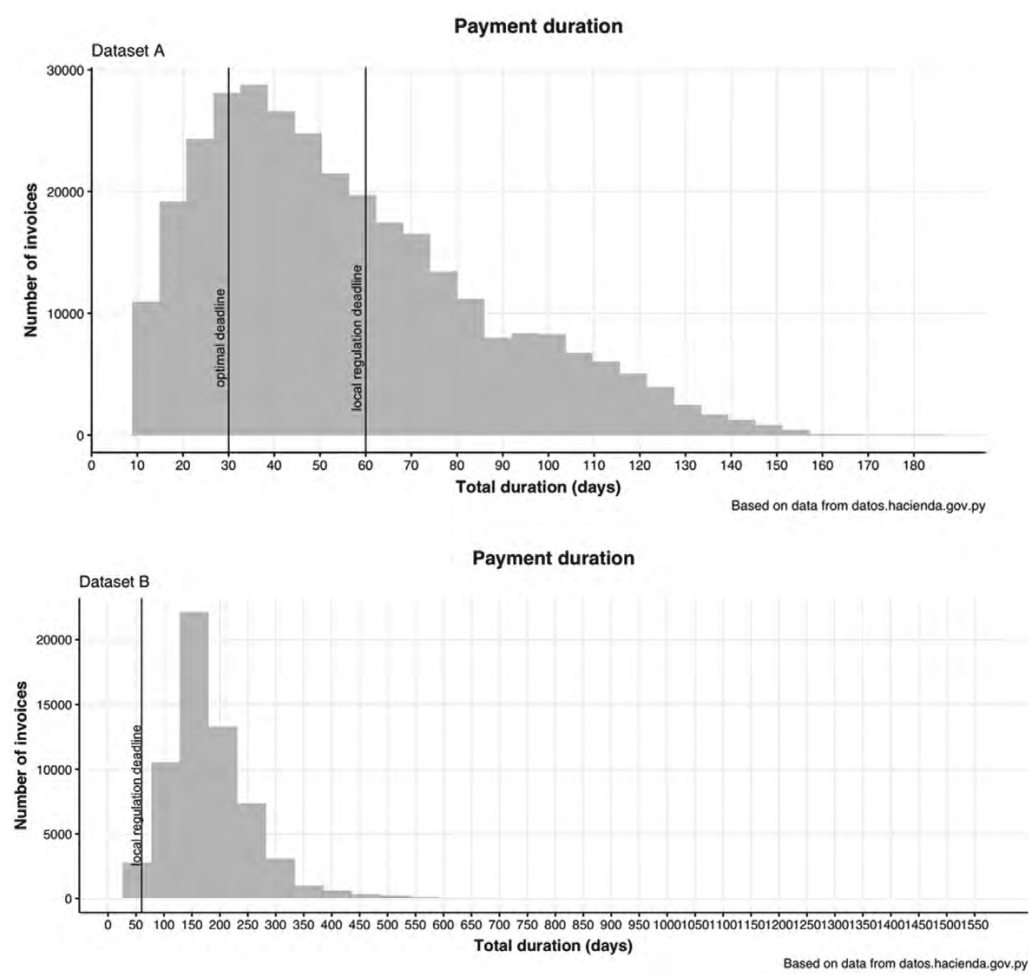
When segmented by year, we found that the median duration spiked after 2012 (see Table 4), it increased from 37 days to more than 52 for the subsequent years. Between 2011 and 2012, there were pay rises approved for public servants, which increased the spending in wages by $44 \%$ between 2011 and 2017 . In contrast, the spending in the budget items related to public contracts only grew $11 \%$ on the analysed period. This caused liquidity problems for the public administration, which had more trouble assigning funds to pay contracts.

Table 4. Median payment duration by year (Dataset A)

\begin{tabular}{l|c|c}
\hline Year & $\mathbf{n}$ & $\begin{array}{c}\text { Median payment } \\
\text { duration (days) }\end{array}$ \\
\hline 2011 & 33894 & 34 \\
\hline 2012 & 50309 & 37 \\
\hline 2013 & 31970 & 58 \\
\hline 2014 & 44632 & 57 \\
\hline 2015 & 50868 & 56 \\
\hline 2016 & 49941 & 56 \\
\hline 2017 & 54369 & 52 \\
\hline
\end{tabular}

This change is well illustrated in Figure 3, where we see an increase in payment times in the first and last stages of the payment process. While the invoice stage has the longest median duration of 22 days, the TO stage increased from a median of five days in 2011 to between 13 to 20 days in the subsequent years. In this last stage, the treasury has to execute the payments according to the available resources, which were more limited after 2012 .

Figure 3. Payment duration by stage

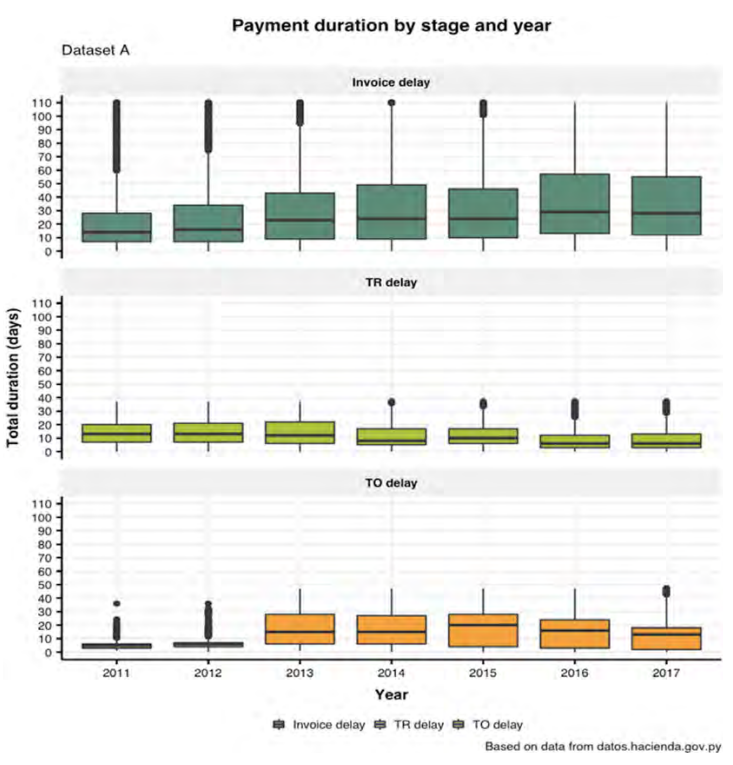


Figure 4 shows a more detailed picture of the change in average duration times by stage. For instance, it is clear that after 2012 procuring entities increased the time they spent loading the invoices in the system and approving the obligations, while the Treasury took longer creating a transfer order after they received a transfer request from the procuring entity.

Figure 4. Average duration by stage and year

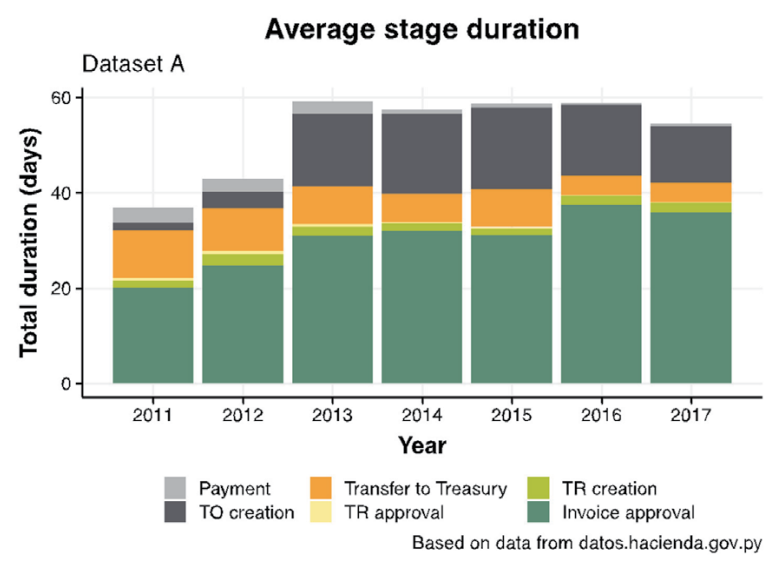

Moreover, the first stage of the process is the one that takes longer, regardless of the institution (see Figure 5). According to Treasury officials the main cause for this delay is that invoices cannot be loaded into the system and then approved if there is not a cash plan assigned by the Treasury, to pay those obligations. The main problem at this stage is that in practice there is a difference between the projected spending budget and the actual income budget that is financed through tax revenues, thus, the entities might not receive all their projected resources for a certain period. However, since the obligations are not recorded into the system, the Treasury has no way of knowing how to prioritise the assignment of resources to institutions that have a large number of bills to pay, which contributes to the delay. Our recommendation would be to improve cash planning and management, to reduce timing problems between payments becoming due and the availability of funds to pay them. For instance, if the system allowed loading the invoices prior to having a cash plan, the Treasury could identify how much resources to distribute according to the needs of each entity.

Moreover, the duration is also affected by the funds used to pay the invoices. It takes longer to pay invoices that depend on Treasury funds (55 days), than those using institutional resources (36 days). To explore this relationship further, we used the Kaplan-Meier curves. As it follows in Figure 6, the curves do indicate a difference between the groups: the invoices that use Treasury funds, take longer to be paid (higher survival probability), than those using institutional funds. 
Figure 5. Average payment duration by institution

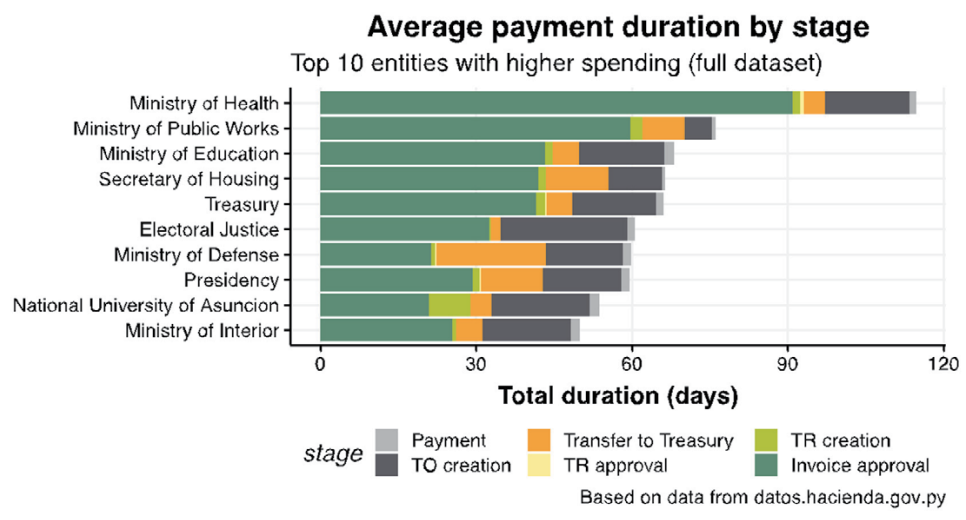

Figure 6. Payment duration by type of funds (Kaplan-Meier curves)

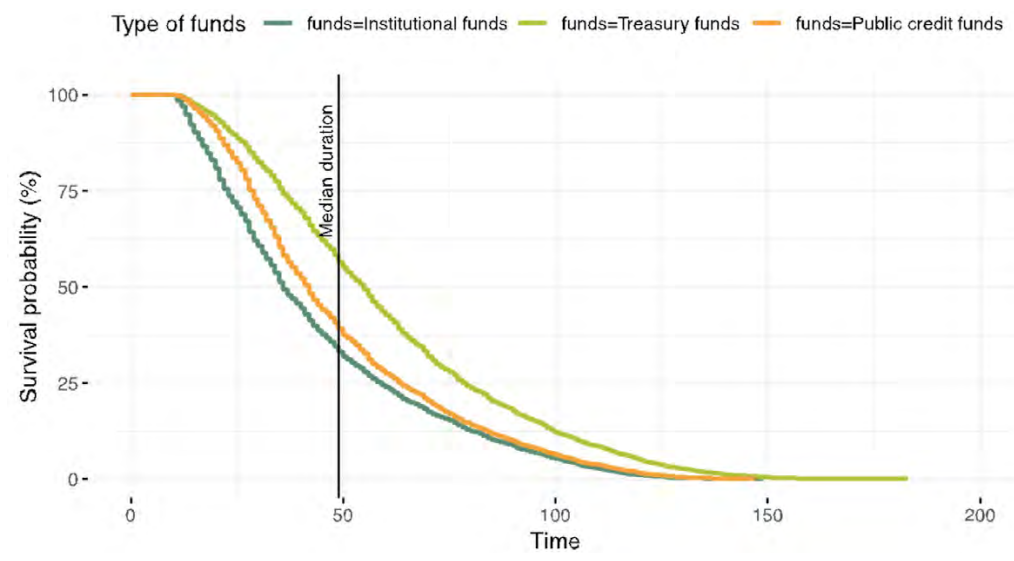

As shown in Figure 7, using Treasury funds delays two stages of the process: the invoice stage, since institutions cannot load the invoices into the system without a cash plan (as explained above), and the TO stage, since the Treasury cannot pay for the obligations if there are no available resources. On the contrary, bills that use public credit funds and institutional resources, do not need a cash plan to create obligations in the first stage, and once the transfer order reaches the Treasury, the funds are available to execute the payment. However, for these two types of funding, the invoice stage has a median duration of more than 22 days, which could be a sign of inefficiencies inside the procurement agencies and not a result of budget constraints. 
Figure 7. Payment duration by type of funds

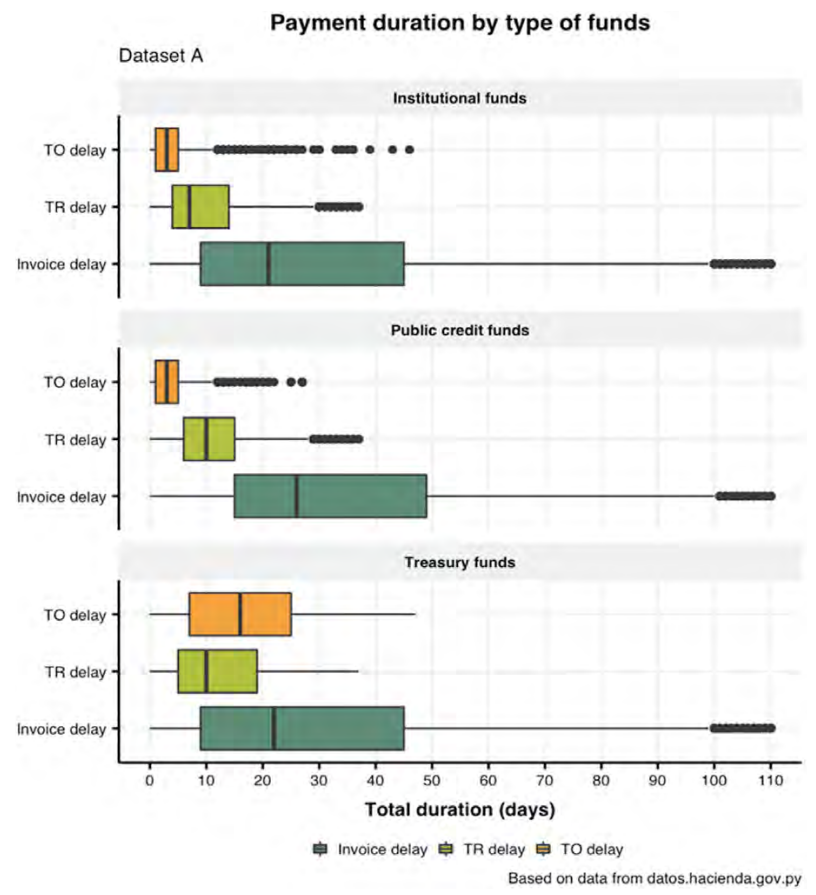

\section{Duration by institution}

We divided the institutions by their size, according to their current payroll, to explore if the size of the entity could indicate a difference in payment times. Our hypothesis is that larger institutions (with more than 10000 employees) have a larger volume of invoices to pay and might have more complicated bureaucratic processes, than smaller entities (less than 1000 employees). As shown in Figure 8, the Kaplan-Meier curves show a significant difference between the groups. Large institutions have a higher survival probability (meaning they take longer to pay invoices) than smaller entities. While $50 \%$ of the invoices in small and median institutions are paid in less than 50 days, larger entities take longer.

When calculating the duration by institutions (in general), there seems to be important differences of payment times, which can be a sign of different practices between the entities. The Ministry of Health (the second in size) has a median payment duration of 73 days (without outliers), while the Foreign Ministry (median size) pays invoices with a median of 22 days. Only 6 of the 41 institutions analysed $^{13}$ have a median duration of less than 30 days.

13 For this part, we only analysed the institutions where data was available for the complete period 2011-2017. 
Figure 8. Payment duration by institution size (Kaplan-Meier curves)

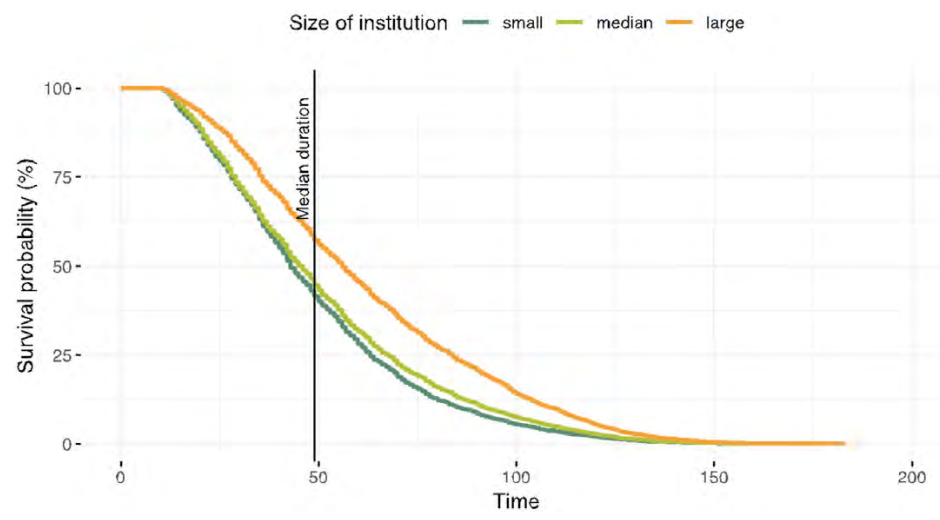

Table 5. Median and maximum duration by institution (top ten with higher spending)

\begin{tabular}{l|c|c|c|c}
\hline Institution & $\begin{array}{c}\text { Median } \\
\text { duration } \\
\text { (Dataset A) }\end{array}$ & $\begin{array}{c}\text { Maximum } \\
\text { duration } \\
\text { (Dataset A) }\end{array}$ & $\begin{array}{c}\text { Median } \\
\text { duration } \\
\text { (Dataset B) }\end{array}$ & $\begin{array}{c}\text { Maximum } \\
\text { duration } \\
\text { (Dataset B) }\end{array}$ \\
\hline Ministry of Health & 73 & 183 & 191 & 698 \\
\hline Ministry of Finance & 56 & 166 & 155 & 468 \\
\hline Ministry of Public Works & 48 & 175 & 177 & 678 \\
\hline Presidency & 48 & 175 & 144 & 508 \\
\hline Ministry of National Defence & 47 & 180 & 138 & 753 \\
\hline National Secretary of Housing & 47 & 160 & 184 & 492 \\
\hline Ministry of Education & 45 & 155 & 154 & 408 \\
\hline National University of Asunción & 40 & 169 & 122 & 485 \\
\hline Electoral Justice & 35 & 154 & 104 & 419 \\
\hline Ministry of Interior & 34 & 160 & 104 & 749 \\
\hline
\end{tabular}

Moreover, besides having the longest median duration, the Ministry of Health is the second with the highest spending in payments, with an accumulated real spending of approximately USD 772 million (18\% of the total), in the analysed period. Nevertheless, the delays in the Ministry of Public Works can be the costliest since this institution accounts for $45 \%$ of the total spending in public procurement payments. The difference in the duration of these two institutions could be the funds used to pay the invoices: while $68 \%$ of the Ministry of Health's invoices were paid using Treasury funds, the Ministry of Public Works paid $60.7 \%$ of its bills with funds from the Public Credit. As explained above, using Treasury funds causes delays in two stages of the process, however, Figures 9 and 10 show that both entities are inefficient at loading the invoices regardless of the type of funds, which contributes to extending the duration. Thus, it is necessary to evaluate the payment practices in these entities to find the cause for the delays. 
Figure 9. Payment duration by type of funds

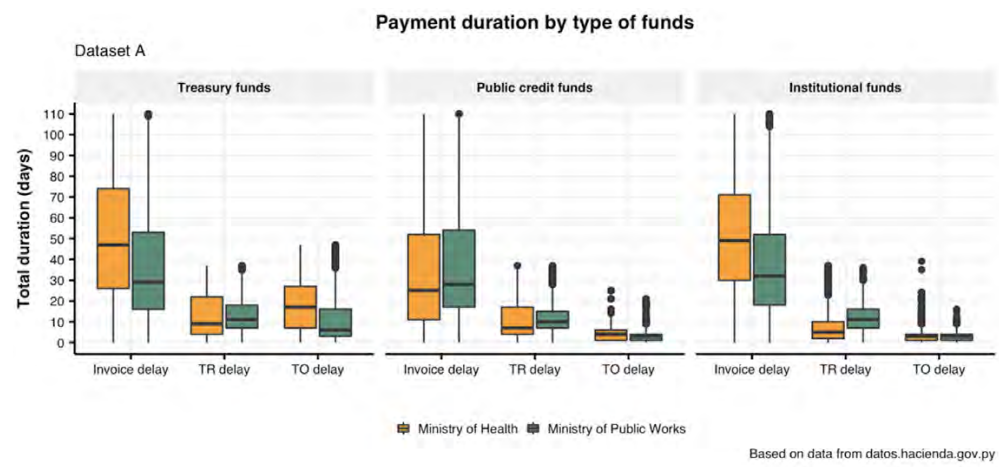

Figure 10. Payment duration by funds and stages

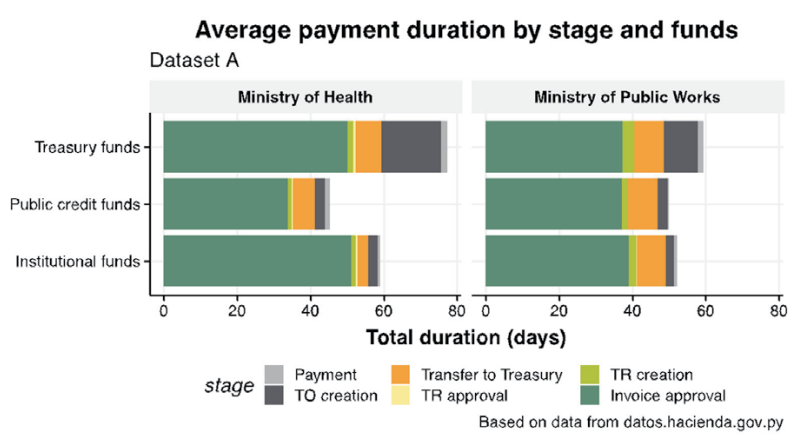

Providers and type of purchase

On the other hand, out of the 4742 providers that received payments in our sample, $80 \%$ of them had more than half their invoices paid after 30 days. Only $8 \%$ of the contractors were paid without a delay. Thus, payment delays are common and affect most of the participants in the procurement processes. In addition, for the larger sample, providers that receive transfers from the government suffer from the longest median duration of 70 days (see Table 6). This is a special case of the Ministry of Education that uses transfers to buy food for schools. In addition, goods and materials have a median duration of 56 days, while invoices related to services or infrastructure are paid faster, with a median of 47 and 43 days, respectively. For the extreme values dataset, the median duration of goods and services, of 177 days is similar to the one of investment works of 176 . We would expect that smaller invoices and simpler contracts, like the ones related to goods and materials are easier to pay than works of infrastructure that tend to be costlier, however, this does not seem to be the norm in Paraguay's public procurement. This can be due to the funds 
used to pay the invoices (as explained above) or that some providers might have more negotiation power when executing contracts and demanding payments. Nonetheless, the lack of information about the companies regarding their size, sector and financial characteristics, impedes a more detailed analysis and this could be explored in future works.

Table 6. Duration by type of purchase (Dataset A)

\begin{tabular}{l|c|c|c}
\hline Type of purchase & $\mathbf{n}$ & $\begin{array}{c}\text { Median } \\
\text { duration }\end{array}$ & $\begin{array}{c}\text { Maximum } \\
\text { duration }\end{array}$ \\
\hline Services & 156,591 & 47 & 175 \\
\hline Goods and materials & 128,209 & 56 & 180 \\
\hline Exchange goods & 251 & 41 & 133 \\
\hline Investment & 30,498 & 43 & 183 \\
\hline Transfers & 434 & 70 & 155 \\
\hline
\end{tabular}

\section{Seasonal trends}

We also observed seasonal trends and found that payments tend to increase in the last quarter of the year, before the end of the fiscal year in December (see Figure 11). In 2013, 2014 and 2015, there is also a peak in May that might be caused by the time it takes to execute payments. Thus, the invoices issued at the beginning of the year start to be paid at the end of the first quarter. In addition, there were no payments registered in January, in any of the years analysed, which can be due to lack of budget or liquidity in public institutions. In comparison, the issue of invoices peaks for most of the years between July and September. In general, there is a lag between the issue of invoices and payments, which confirms there are delays. Providers might be aware of this problem, and thus issue their invoices at particular times in order to guarantee payments before the end of the year.

Figure 11. Invoices billed and paid per month

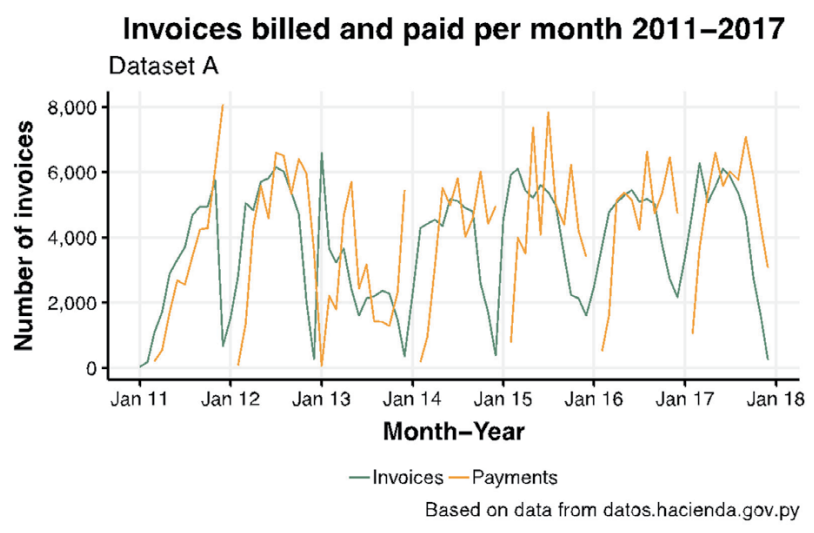


We also observed that invoices are accumulated before the Treasury pays them. As shown in Figure 12, the stock of unpaid bills is higher in the second and third quarters and decreases at the end of the year. This means that providers that present invoices at the beginning of the year face longer delays and thus higher costs than those with payments in the last months. In fact, the median duration of payments for bills issued in the first quarter is 66 days, while it reduces to 34 days for invoices presented after October; in the case of invoices presented in the second and third quarters, the median duration is 49 days. By taking into account the seasonal trends institutions can better plan their procurement processes, in order to schedule payments in periods where there is enough liquidity to pay promptly; or, if possible, distribute the stock of invoices through the year, instead of concentrating them in a particular period.

Figure 12. Unpaid invoices by year

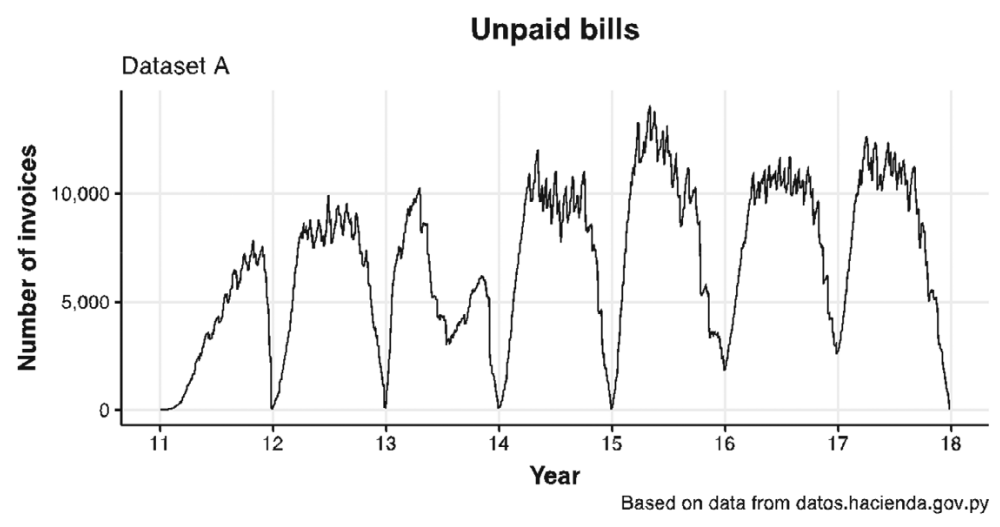

\section{Survival model}

Finally, we estimated a parametric model with a Weibull distribution, to calculate the effect of the different covariates on survival time. The results are presented in Table 6 .

We found that a one per cent increase in the invoice amount shortens survival time by 0.97 times, this means that larger invoices are paid faster, under the assumption that all variables are held constant. However, the same increase in the amount of the contract extends payment time (survival) by 1.03 times, so the effect might seem contradictory. A possible explanation could be that for bigger contracts the payments are segmented and thus the invoices have a smaller amount.

Using Treasury funds to pay the invoice increases survival time (payment takes longer) by 1.31 times in comparison to using institutional or public credit funds. Moreover, institutions with more than 10000 employees extend survival time by 1.43 times in comparison to smaller entities with a payroll of less than 
1000 . As explained in our descriptive results, larger institutions have a higher volume of invoices and the payment process can be more complex. Also, an increase in the institutional budget execution reduces survival time, showing that entities that are more efficient in executing public resources tend to pay providers faster.

Table 6. Coefficient estimates

\begin{tabular}{l|c|c|c}
\hline & \multicolumn{3}{|c}{ Weibull model estimation } \\
\hline & Coeff. & \multicolumn{2}{c}{ exp(coeff.) } \\
\hline Invoice amount (log) & -0.0299 & 0.9705 & $* * *$ \\
\hline Treasury funds & 0.2747 & 1.3161 & $* * *$ \\
\hline Institution size (base=small) & & & \\
\hline Median & 0.1983 & 1.2193 & $* * *$ \\
\hline Large & 0.3578 & 1.4302 & $* * *$ \\
\hline Institutional budget execution & -1.5322 & 0.2161 & $* * *$ \\
\hline Contract amount (log) & 0.0311 & 1.0311 & $* * *$ \\
\hline Type of purchase (base= Services) & & & \\
\hline Goods and materials & 0.0454 & 1.0465 & $* * *$ \\
\hline Investment & 0.0360 & 1.0367 & $* * *$ \\
\hline Other & 0.1513 & 1.1633 & $* * *$ \\
\hline N & 296299 & & \\
\hline AIC & 2771433 & & \\
\hline Log-likelihood & -1385706 & & \\
\hline Statistical significance & $* * * p<0.01$ & & \\
\hline
\end{tabular}

Finally, invoices related to services purchased are paid faster than those related to investment or goods and materials. For instance, investment contracts extend payment time by 0.03 times, in comparison to services. Other previous work (Gori et al. 2017) had found that infrastructure contracts are associated with longer delays, and thus this could affect payments. However, the invoices related to goods and materials have a larger effect on payment time than investment. These results show areas where institutions might be able to improve in order to reduce delays in payments.

\section{Cost estimation}

According to our estimates, between 2011 and 2017 the total cost of late payments (after 30 days) was of USD 81.07 million ( $0.28 \%$ of 2017 nominal GDP), meaning that if this new deadline is established and the institutions pay on time, costs could be reduced by this amount. Considering payments are overdue if they are paid in more than 45 days, the cost was of USD 61.12 million 
( $0.21 \%$ of GDP), and in the case of a 60 -day deadline the cost was of USD 47.11 million ( $0.16 \%$ of GDP). Moreover, the cost of the total payment duration was of USD 142.29 million ( $0.48 \%$ of 2017 nominal GDP).

Finally, the cost of delaying the invoice stage in more than 15 days is USD 68.63 (0.23\% of GDP). As explained in the descriptive results, the invoice stage is the one that accounts for most of the delay, and thus has the biggest cost of the different stages of the process. The complete results are shown in Table 7.

Table 7. Cost estimation of late payments 2011-2017 (full dataset)

\begin{tabular}{l|c|c}
\hline Deadline & $\begin{array}{c}\text { Cost in millions } \\
\text { of dollars }\end{array}$ & $\begin{array}{c}\text { Percentage of } \\
\text { 2017 GDP }\end{array}$ \\
\hline 30 days & 81.07 & $0.28 \%$ \\
\hline 45 days & 61.12 & $0.21 \%$ \\
\hline 60 days & 47.10 & $0.16 \%$ \\
\hline 15 days (invoice stage) & 68.63 & $0.23 \%$ \\
\hline Total cost of payment duration & 142.29 & $0.48 \%$ \\
\hline
\end{tabular}

The results can be interpreted as the costs private providers had to incur in order to face the liquidity problem caused by payment delays. Having longer deadlines, such as 60 days as stated in national regulations, could benefit public institutions since they have to recognise less interests to providers if the payments are delayed and claims are presented. However, this has a negative effect on contractors and at an aggregated level, since they have to find resources to cover their financial needs for the whole payment period, not only after the 60-day deadline. Moreover, since providers know there are delays in payment times, they might internalise the financial cost in the cost structure of the contract, which translates into higher prices for the public administration.

A possible solution to this problem could be to reduce payment deadlines in regulations, to force institutions to accelerate their payment processes and thus reduce the aggregated financial cost. For instance, if the new deadline is set in 30 or 45 days, costs could be reduced by USD 81 million and USD 61 million, respectively. Nevertheless, this must be accompanied by better and more efficient practices inside the procuring entities since, if only the legislation is changed but not the internal processes, this may imply that the institutions might have to recognise more interests for late payments to suppliers. For instance, an evaluation of the European Union Late Payment Directive in 2014, concluded that a new regulation that forced institutions to pay invoices in 30 days or less had not greatly reduced payment times in most of the European countries, but stakeholders argued that legislation had obliged governments to act and improve their payment practices (Valcani Vicari Associati et al. 2015).

When analysed by year, the cost has risen since 2011 , but remained relatively constant after 2016. The difference between 2011 and other years is a result of 
the change in duration in the different stages of the process, as explained in the descriptive results. As a percentage of GDP, the total cost of late payments was of $0.004 \%$ of GDP in 2011 and then rose to $0.058 \%$ of GDP in 2015 (Figure 14). When considering the total payment duration cost, the number rises to $0.09 \%$ of GDP in 2016. In comparison to previous studies about the aggregate cost of late payments in other countries in Europe, Paraguay has a similar cost to countries like Italy or Spain, with a cost close to 1\% of annual GDP (Connell 2014). Moreover, the cost is higher in the first quarter of the year and reduces significantly in the last quarter, showing that seasonal trends in payments can increase the costs at specific periods of the year.

Figure 13. Cost of delayed payments by year

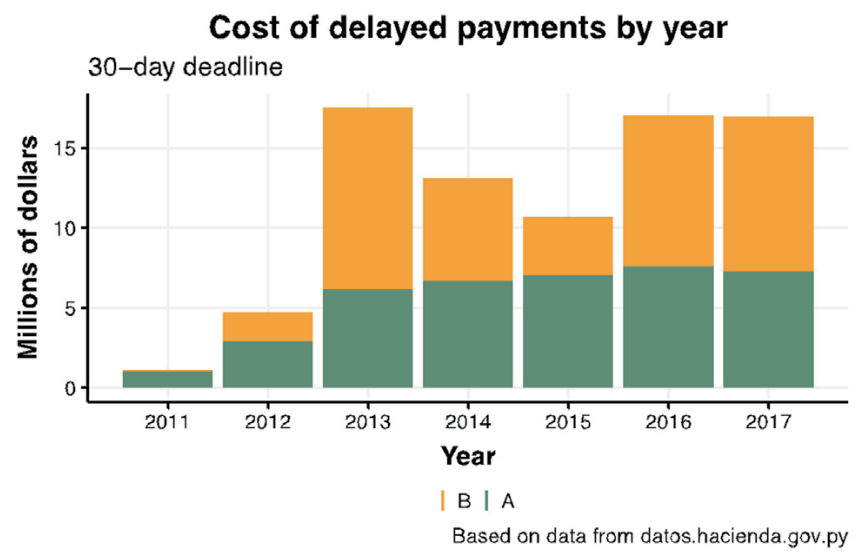

Figure 14. Cost as a percentage of GDP

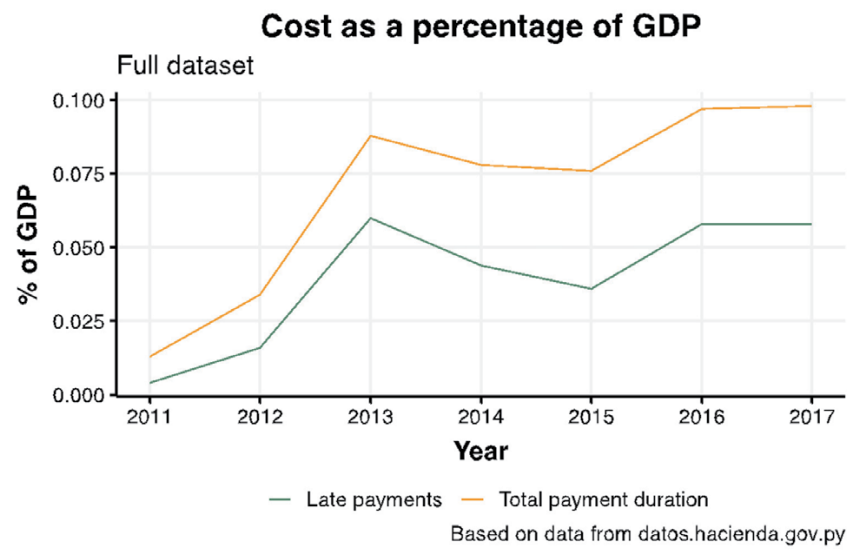


As expected, the larger cost is concentrated in the first stage of the process which accounts for USD 95.8 million or $67 \%$ of the total payment duration cost. Changes can be made in this stage in order to improve the process. For instance, if a 15-day deadline is established in this step to encourage institutions to accelerate their payments, the costs could be reduced by $48 \%$.

Figure 15. Total cost by stages

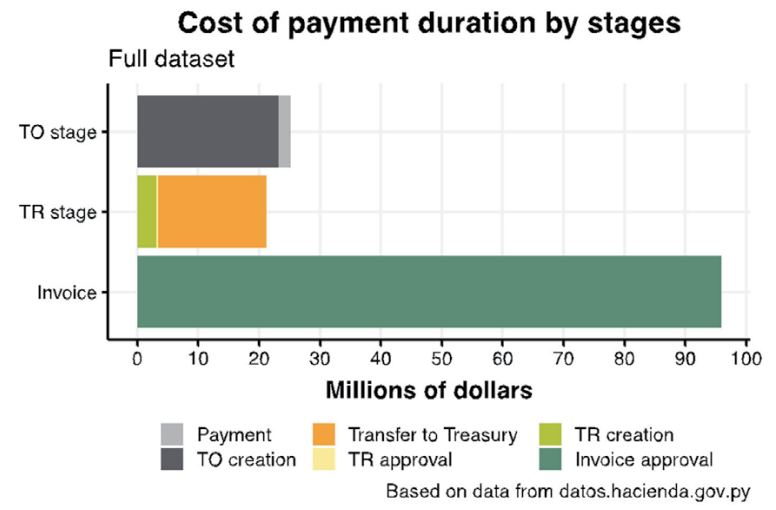

Finally, three entities concentrate $73.9 \%$ of the total payment duration cost. The Ministry of Public Works accumulates $37 \%$ of the total cost, the Ministry of Health $30 \%$ and the Ministry of Education 5.9\%. This means that procuring payment practices must be improved in these institutions in order to obtain the biggest savings.

Figure 16. Cost of delayed payments by institution

Total cost by institution

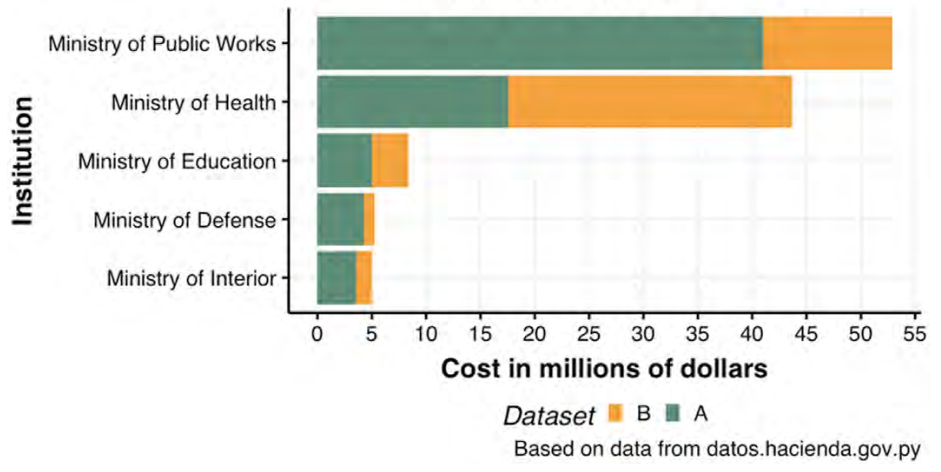




\section{Conclusion}

This work shows how to calculate the cost of the duration and delay of payments and the variables that affect payment time, using detailed open contracting data. We found that the total cost of the payment duration in Paraguay, between 2011 and 2017, was of USD 142.29 million, equivalent to $0.48 \%$ of Paraguay's 2017 Gross Domestic Product. Considering a 30-day deadline as an acceptable payment time, the cost of late payments was of USD 81.07 million. In general, procuring entities take 55 days on average to pay invoices, while the international optimal deadlines are established in 30 days. For some institutions, the duration can extend for more than a year, which shows there are inefficiencies in the procurement payment process.

Moreover, two ministries, Health and Public Works, concentrate $67 \%$ of the total cost, so the corrective efforts should be concentrated in these entities. There is also evidence that the funding source, the type of purchase, the size of the institution and its budget execution affect payment duration times. Besides, the first step of the payment procedure (invoice stage), which is not regulated, is the one that takes longer. Our recommendation would be to revise the procurement practices at this stage in order to shorten the delays. If a deadline of 15 days is met, costs could be reduced by $48 \%$. Moreover, if the total payment deadline is established in 45 or 30 days since the invoice issuance, the total payment duration cost could be reduced by $42 \%$ or $52 \%$, respectively.

We conclude that there are two main areas of improvement in the payment process. First, regulate the first stage and establish a deadline to force institutions to modify their practices to load invoices into the system more quickly. This is particularly important for invoices paid with institutional and public credit funds, since there is no justification to delay the process if there are resources available to pay. In the case of bills paid with Treasury funds, our recommendation would be to modify the steps in the process, so that invoices can be loaded into the system without a cash plan. This can help the Treasury identify which payments are coming due and distribute the funds accordingly.

Moreover, this work demonstrates how public procurement open data can be analysed to generate high value insights for the public administration, in order to improve contracting practices and save public funds. Our methodology can be implemented in any country that publishes payment and contracting data in open formats, and aims to serve as an example of how institutional efforts to publish detailed open data about all the steps of the procurement process, can pay off when valuable insights are derived from its analysis.

Our study faced some limitations regarding mainly the availability of data. It would be useful to have more disaggregated data about the providers in order to determine whether the delays are affecting more small, medium enterprises or big companies. Even though the cost can be higher to bigger providers that obtain larger contracts, for smaller enterprises it could be harder to access credit 
or to cover the lack of liquidity caused by the delay. In addition, not having information about the characteristics of the firm (size, sector) can result in an underestimation of the cost, since the interest rates can be different. Having open data about beneficial ownership could help expand the analysis to determine if there are clusters of providers that are more affected by the delays, and could also be useful to estimate the effect of late payments on the exit rate of firms. In addition, the analysis could be extended if payment information of other institutions in the public sector published payment data in open formats.

Finally, this investigation could be extended with a dataset of the cash plan, to compare the availability of resources with the payment information, in order to determine more efficient ways to redistribute the resources and thus reduce payment duration.

\section{REFERENCES}

Balaeva O \& Yakovlev A (2017) Estimation of costs in the Russian public procurement system. International Journal of Procurement Management 10(1). DOI 10.1504/ IJPM.2017.10000827

Cameron C \& Trivedi P (2005) Microeconometrics: Methods and Applications. Cambridge: Cambridge University Press

Checherita-Westphal C, Klemm A \& Viefers P (2016) Governments' payment discipline: The macroeconomic impact of public payment delays and arrears. Journal of Macroeconomics 47: 147-165. DOI 10.1016/j.jmacro.2015.12.003

Connell W (2014) The economic impact of late payments. Directorate General Economic and Financial Affairs (DG ECFIN) Economic Paper No. 531. Brussels: European Commission

Diamond J \& Schiller C (1987) Government arrears in fiscal adjustment programs. FinanzArchiv / Public Finance Analysis 45(2): 229-259

Fiordelisi F, Mare D, Radic N \& Ricci O (2012) Government late payments: The effect on the Italian economy - I ritardi di pagamento della Pubblica Amministrazione. Financial Intermediation Network of European Studies (FINEST) Report No. 1. https:// assifact.it/wp-content/uploads/2016/12/FINEST-Report_24042012.pdf

Flynn S \& Pessoa M (2014) Prevention and management of government expenditure arrears. IMF Technical Notes and Manuals 14/03. Washington, DC: IMF

Giussani B, Guardiola U \& Ospina J (2016) Evaluación PEFA de la Gestión de Finanzas Públicas en Paraguay. PEFA. https://pefa.org/assessments/paraguay-2016

Gori G, Lattarulo P \& Mariani M (2017) Understanding the procurement performance of local governments: A duration analysis of public works. Environment and Planning C: Politics and Space 35(5): 809-827. DOI https://doi.org/10.1177/0263774X16680109

Guccio C, Pignataro G \& Rizzo I (2012) Measuring the efficient management of public works contracts: A non-parametric approach. Journal of Public Procurement 12(4): 528-546

Guccio C, Pignataro G \& Rizzo I (2014) Evaluating the performance of public procurement contracts for cultural heritage conservation works in Italy. Journal of Cultural Economics 38(1): 43-70. DOI https://doi.org/10.1007/s10824-012-9194-2

Marchessault L (2013) Open contracting: New frontier for transparency and accountability. World Bank Institute. https://www.open-contracting.org/resources/ open-contracting-a-new-frontier-for-transparency-and-accountability/ 
Open Contracting Partnership (2017) Annual Report 2017. https://www.open-contracting. org/resources/annual-report-2017-serving-transparency-change-public-contracting/

Ramos A (1998) Government Expenditure Arrears: Securitization and Other Solutions. Working paper of the International Monetary Fund No. 98/70. https://www.imf. org/en/Publications/WP/Issues/2016/12/30/Government-Expenditure-ArrearsSecuritization-and-Other-Solutions-2596

Smirnov J (2016) Modelling late invoice payment times using survival analysis and random forests techniques. MSc thesis, Faculty of Science \& Technology, University of Tartu

Strand I, Ramada P, Canton E, Muller P, Devnani S, Bas PD \& Dvergsdal K (2011) Public procurement in Europe: Cost and effectiveness. A Study on Procurement Regulation Prepared for the European Commission. Brussels: London Economics, PricewaterhouseCoopers and Ecorys

Valcani Vicari Associati, Technopolis Group \& Ernst \& Young (2015) Ex-postevaluation of late payment directive. Brussels: European Commission. https://publications.europa. eu/en/publication-detail/-/publication/400ecc74-9a54-11e5-b3b7-01aa75ed71a1

World Bank (2008) Paraguay - Integrated fiduciary assessment (English). Washington DC: World Bank Group http://documents.worldbank.org/curated/ en/620621468070136312/Paraguay-Integrated-fiduciary-assessment

World Bank (2017) Benchmarking public procurement: Assessing Public Procurement regulatory systems in 180 economies. Washington DC: World Bank Group 